\title{
Effects of Testicular and Ovarian Inhibin-Like Activity, Using In Vitro and In Vivo Systems
}

\author{
By \\ F. H. de Jong, R. Welschen*, W. P. Hermans*, \\ S. D. Smith and H. J. van der Molen
}

\begin{abstract}
Inhibin-like activities in charcoal-treated bovine follicular fluid (FF) and medium from cultured Sertoli cells (SCCM) were assayed in an in vitro bioassay system, using cultured pituitary cells. Addition of both fluids resulted in parallel dose-dependent decreases of the concentration of follicle-stimulating hormone (FSH) in the medium, both in the presence or absence of luteinizing hormone-releasing hormone (LH-RH).

A single injection of $\mathrm{FF}$ into immature and adult male and female rats resulted in decreased peripheral levels of $\mathrm{FSH}$, but not of $\mathrm{LH}$, after 4 or $8 \mathrm{~h}$. This decrease was larger and occurred faster in adult female rats than in prepubertal female animals. Injection of FF into adult female rats, immediately after unilateral ovariectomy (ULO) prevented the specific increase of FSH levels, occurring in control animals. This suppression could not be obtained after treatment with steroids.

Daily treatment of adult female or immature male rats for periods longer than 5 days did not result in prolonged suppression of circulating FSH concentrations; LH levels were significantly increased. The female animals showed cyclic vaginal smear changes and normal ovulation; in the male rats testis weight and numbers of spermatogenic cells were reduced.

It is concluded that testicular and ovarian inhibin-like activities have similar properties. Injections of $\mathrm{FF}$ into male and female rats cause similar effects on FSH and LH. The effect of FF in ULO-animals suggests that inhibin could play a role in the short-term regulation of the number of developing follicles in the ovary. Injection of FF into male rats causes a probably transient impairment of spermatogenesis through an initial suppression of FSH.
\end{abstract}

Key words: inhibin - follicular fluid - Sertoli cell - pituitary cell culture FSH regulation - unilateral ovariectomy. 
Inhibin, a substance which specifically suppresses the secretion of folliclestimulating hormone (FSH) from the pituitary, was postulated to be present in the testis by McCullagh in 1932. Since that time, inhibin-like activity was shown to be present in testicular fluids (Setchell \& Jacks 1974; Franchimont et al. 1975), in testicular tissue (Keogh et al. 1976; Nandini et al. 1976) and in follicular fluid (FF) from the ovary (de Jong \& Sharpe 1976; Marder et al. 1977; Welschen et al. 1977).

The aim of the first part of the present study was to compare the apparent inhibin-like activities from male and female gonads. Medium from cultured Sertoli cells (SCCM), which contains inhibin-like activity (Steinberger \& Steinberger 1976), and bovine FF were tested in an in vitro bioassay system for inhibin-like activity, using cultured pituitary cells.

In the second part of this study the potential of FF to suppress peripheral concentrations of FSH in male and female rats of different ages was investigated. Since the influence of FSH on the gonad is largest in the prepubertal male rat (Means et al. 1976) and in cyclic female animals, these groups were studied during long-term treatment with FF. Moreover, acute effects of FF were investigated in the unilaterally ovariectomized (ULO) rat, where a discrepancy between peripheral levels of FSH and LH occurs (Howland \& Skinner 1973; Ramirez \& Sawyer 1974; Welschen \& Dullaart 1974).

\section{Animal techniques}

\section{Materials and Methods}

Rats, bred in the laboratory and belonging to a Wistar sub-strain (R Amsterdam) were kept under controlled conditions of light (light period 5.00-19.00 h) and temperature $\left(22-24^{\circ} \mathrm{C}\right)$ and received standard dry pellets and tap water ad libitum. Animals were weaned at the age of 21 or 22 days. Female rats reached puberty at 37-42 days of age. Daily vaginal smears were taken from the adult female rats and only rats with at least 2 consecutive 5 day cycles prior to treatment were used. All operations, injections (ip) and blood collections were performed under light ether anaesthesia in female rats. Male animals in the long-term experiment were injected (sc) and decapitated without anaesthesia. At least 6 rats were used in all groups of control and experimental animals, unless otherwise stated.

\section{Follicular fluid}

FF was aspirated from bovine ovarian follicles with diameters between 5 and $20 \mathrm{~mm}$ and treated with charcoal as described previously (Welschen et al. 1977). Charcoal-treated bovine plasma (BP) served as a control fluid in all experiments, since its protein composition is similar to that of FF (Caravaglios \& Cilotti 1957). 
Sertoli cells from testes of 20 to 26 days old rats were prepared and brought in culture as described by Rommerts et al. (1978). Medium from these cells, grown in supplemented Eagle's minimum essential medium (MEM, day 1 to 4 of culture) was obtained by courtesy of Dr. F. F. G. Rommerts.

\section{Pituitary cell culture}

Anterior pituitaries were collected from 10 to 15 adult male rats immediately after decapitation. Dispersed pituitary cells were prepared using a modification of the method described by Denef et al. (1976), which essentially consists of trypsin treatment of the chopped pituitary tissue, followed by dispersion in calcium and magnesium free medium. Cells were cultured at $32^{\circ} \mathrm{C}$ in $2 \mathrm{ml}$ supplemented MEM, to which $10 \%$ foetal calf serum was added. After a preculture period of 3 days, media were renewed and fluids to be tested for inhibin-like activity were added. Culture was continued for a second 3 day period. Media were collected and stored at $-20^{\circ} \mathrm{C}$ until assayed for $\mathrm{LH}$ and FSH. After addition of new medium to the cells, together with the dose of inhibin-like material previously present, culture was continued for 6 h in the presence of $\mathrm{LH}$-releasing hormone ( $\mathrm{LH}-\mathrm{RH}, 50 \mathrm{ng} / \mathrm{ml})$. After collection of the medium, the cells were scraped from the dishes in $2 \mathrm{ml}$ of distilled water. These samples were also assayed for LH and FSH.

\section{Hormone assays}

FSH and LH in culture medium and serum were measured by radioimmunoassay (Welschen et al. 1975). All results are expressed in terms of NIAMDD rat-LH RP-1 and NIAMDD rat-FSH RP-1. Plasma oestradiol and progesterone were also estimated using radioimmunological procedures (de Jong et al. 1973, 1974).

\section{Statistical procedures}

The significance of differences between the results for different treatment groups was assessed using Student's $t$-test or Wilcoxon's two-sample test. Differences were considered significant when $P<0.05$ (two-tailed). Bioassay results were calculated according to Borth (1976).

\section{In vitro experiments}

\section{Results}

Addition of different doses of FF or SCCM to the medium of the cultured pituitary cells caused a dose-dependent suppression of the FSH concentrations 
in the medium harvested after 3 days of culture (Fig. 1). The equations for the regression lines (FSH concentrations, in $\mu \mathrm{g} / \mathrm{ml}$, versus ln (volume added, in $\mu 1)$ ) for FF and SCCM were $\mathrm{y}=0.08-4.53 \mathrm{x}$ and $\mathrm{y}=0.36-3.97 \mathrm{x}$, respectively. The difference in slope was not significant. Correlation coefficients were -0.82 $(\mathrm{n}=16)$ and $-0.84(\mathrm{n}=15)$ and the precision index $(\lambda)$ of the assay was 0.21 . The concentration of inhibin-like activity in the SCCM, relative to the concentration in FF, was $0.70 \times 10^{-3}\left(95 \%\right.$ confidence limits $\left.0.48-1.05 \times 10^{-3}\right)$. LH concentrations in the medium were not affected with amounts of FF up to $50 \mu$ l. However, addition of 100 or $200 \mu \mathrm{l}$ of FF caused a significant increase in $\mathrm{LH}$ release (data not shown), without changing the already maximally suppressed concentration of FSH in the medium. Addition of $200 \mu \mathrm{l}$ of BP did not influence the release of LH and FSH in control dishes. Usually, the addition of SCCM to the pituitary cells in culture did not affect the concentration of LH in the medium. However, occasional batches of SCCM caused a dose dependent increase in the release of $\mathrm{LH}$ during the 3 days culture period (Fig. 1, $\mathrm{r}=0.82$ ).

When the 3 day culture period was followed by a $6 \mathrm{~h}$ period in the presence of LH-RH, again a relationship between the suppression of FSH and in dose

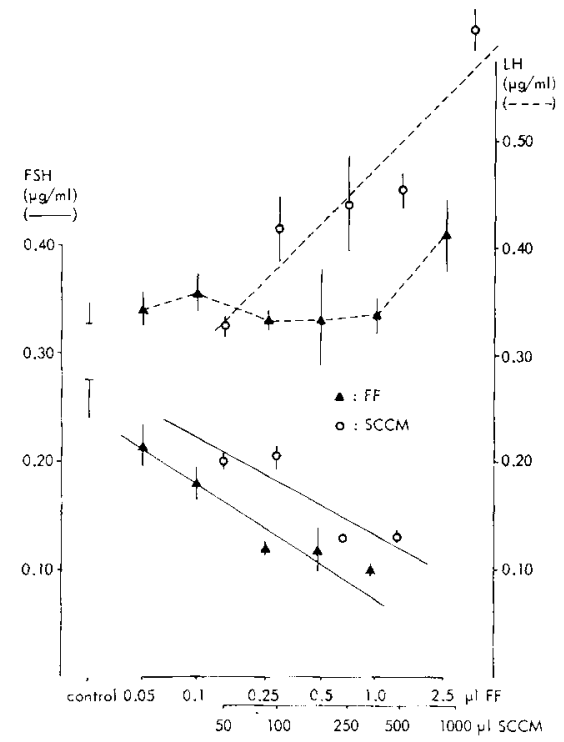

Fig. 1.

Effect of different volumes of follicular fluid (FF) or Sertoli cell conditioned medium (SCCM) on gonadotrophin concentrations in the medium of pituitary cells, cultured for 3 days (means \pm sEM, $n=4$ ). 


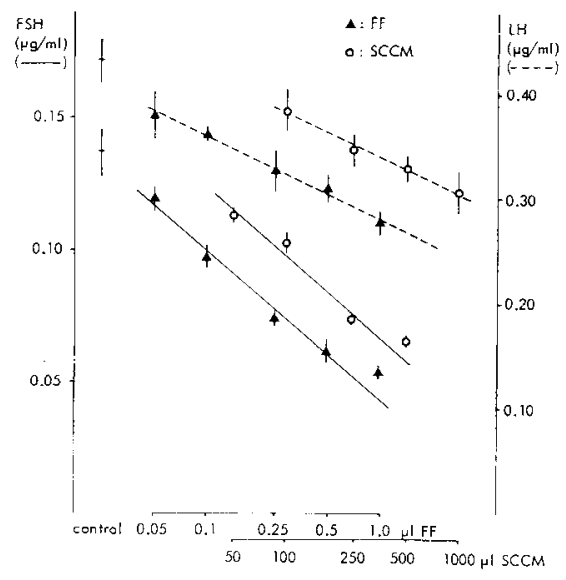

Fig. 2.

Effect of different volumes of follicular fluid (FF) or Sertoli cell conditioned medium (SCCM) on gonadotrophin concentrations in the medium of pituitary cells, cultured for $6 \mathrm{~h}$ in the presence of LH-RH $(50 \mathrm{ng} / \mathrm{ml})$ after a previous 3 day culture with the same volume of FF or SCCM (means $\pm \mathrm{SEM}, \mathrm{n}=4$ ).

was observed for both FF and SCCM (Fig. 2). The equations for the regression lines were $\mathrm{y}=0.04-2.48 \mathrm{x}$ and $\mathrm{y}=0.21-2.47 \mathrm{x}$, respectively; $\mathrm{r}=0.95 \quad(\mathrm{n}=16)$ and $0.93(n=12)$. The precision index under these conditions was 0.11 . The concentration of inhibin-like activity in SCCM, relative to that in FF, was $1.01 \times 10^{-3}\left(95 \%\right.$ confidence limits $\left.0.84-1.22 \times 10^{-3}\right)$. Both FF and SCCM also suppressed the concentrations of LH in the medium in a dose dependent way (regression lines: $\mathrm{y}=0.28-3.40 \mathrm{x}$ and $\mathrm{y}=0.53-3.39 \mathrm{x}, \mathrm{r}=0.80(\mathrm{n}=16)$ and 0.69 $(\mathrm{n}=15)$, respectively, $\lambda=0.35$ ).

Finally, the amount of FSH, remaining in the cells after these treatments, was negatively correlated with the doses of FF or SCCM previously added (regression lines: $\mathrm{y}=0.15-1.21 \mathrm{x}$ and $\mathrm{y}=0.21-1.10 \mathrm{x}, \mathrm{r}=0.68(\mathrm{n}=24)$ and 0.72 $(\mathrm{n}=19)$, respectively). The cellular content of LH was not affected by the doses of FF used. In the experiment where LH levels were increased in the medium during the 3 day culture period after addition of SCCM, the cellular content of LH in the same dishes was suppressed in a dose dependent way (data not shown).

These results could not be explained by damage to the cells, by degradation of FSH or LH-RH, or by the presence of steroids in charcoal-treated FF or in SCCM. 
In vivo experiments

Effect of different doses of FF on serum concentrations of FSH. - Prepubertal (15 days old) and adult (75 days old) male and female (dicestrus 2) rats, which had been gonadectomized 2 days earlier, were injected with increasing doses of FF or BP at $9.00 \mathrm{~h}$ and bled $8 \mathrm{~h}$ later. The relationship between the dose of FF injected and serum FSH concentrations is shown in Fig. 3. A significant decrease of FSH levels was observed with doses of $0.125 \mathrm{ml} / 100 \mathrm{~g}$ body weight or more in all 4 groups. A maximal suppression of FSH to about $60 \%$ of control levels was found after injection of 0.25 or $0.50 \mathrm{ml} / 100 \mathrm{~g} \mathrm{~b}$. w. in ail groups, except for the adult female rats, where FSH was suppressed to about $40 \%$ of control levels with these dosages.

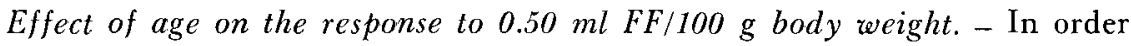
to study at what age female rats start to show the stronger suppression of peripheral concentrations of FSH after injection of a relatively large dose of FF, female rats with ages of 5, 25 and 35 days were added to the age groups shown in Fig. 3. Furthermore, groups of intact animals were included since pilot experiments had shown that after gonadectomy of adult female rats the FSH response to injection of FF decreased with increasing time after the operation. In order to investigate the time course of the response animals were bled at 4 and $8 \mathrm{~h}$ after the injection of FF. The results of this experiment are summarized in Fig. 4. The response of the 2 days gonadectomized animals after $8 \mathrm{~h}$ was comparable to that shown in Fig. 3. Neither in adult nor in prepubertal male rats a significant suppression of FSH was observed $4 \mathrm{~h}$ after injection

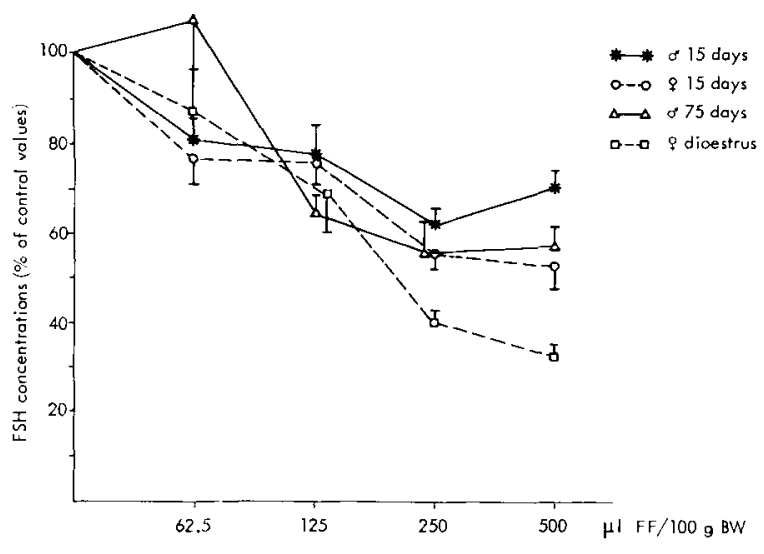

Fig. 3.

Effect of different volumes of follicular fluid on serum concentrations of FSH in gonadectomized male and female rats $8 \mathrm{~h}$ after injection (means \pm SEM). All concentrations are relative to values in bovine plasma treated controls. 


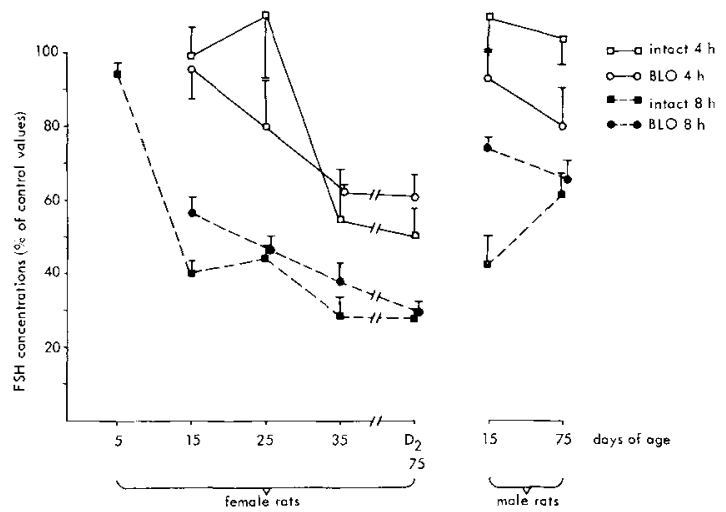

Fig. 4.

Influence of age on the effect of the injection of $0.5 \mathrm{ml}$ of follicular fluid/100 $\mathrm{g} \mathrm{b}$. w. into intact and gonadectomized (BLO) male and female rats of different ages on the relative serum level of FSH, 4 and $8 \mathrm{~h}$ later (means \pm SEM).

of FF. The response in intact adult males was similar to that in the gonadectomized group, but the intact 15 days old males showed a significantly larger suppression than the castrated animals of the same age.

In female rats a response after $4 \mathrm{~h}$ was found from the age of 35 days cnwards. There was an increase of the FSH suppression with age: at day 5 no significant suppression occurred, while at 35 days of age an adultlike response was observed. However, the absence of FSH suppression on day 5 does not reflect an absolute refractoriness to $\mathrm{FF}$ : in an additional group of rats, injected daily for 3 days (days 3-5) with $0.1 \mathrm{ml} \mathrm{FF}$ or BP, a significant effect of FF was found (352 \pm 11 and $504 \pm 14 \mathrm{ng} / \mathrm{ml}$, respectively, $\mathrm{n}=4$, blood from 4 animals was pooled in each sample).

Serum concentrations of $\mathrm{LH}$ in the $25 \mathrm{FF}$ treated groups of rats were not significantly different from those in the BP treated controls with the exception of 3 groups: decreased LH levels were observed in the intact adult males $4 \mathrm{~h}$ after injection and in the adult females (at $8 \mathrm{~h}$ ) and increased $\mathrm{LH}$ concentrations were measured in the castrated adult males (at $8 \mathrm{~h}$ ).

Influence of FF and steroids on serum FSH levels after unilateral ovariectomy. - Adult female rats were unilaterally ovariectomized or sham operated at $9.00 \mathrm{~h}$ on the second day of dioestrus. L.H, FSH, progesterone and oestradiol were estimated in serum or plasma obtained 4 and $8 \mathrm{~h}$ later. A second group of rats was treated in a similar way, and received either injections of $\mathrm{BP}$ or FF or silastic implants with or without progesterone $(5 \mathrm{~cm}$ long, inner diameter $3.0 \mathrm{~mm}$, outer diameter $3.8 \mathrm{~mm}$, placed in phosphate buffered saline during 


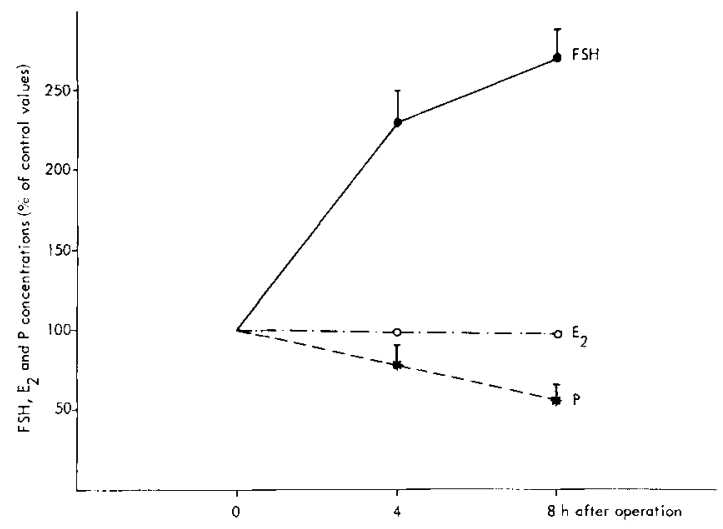

Fig. 5 .

Relative serum concentrations of FSH, progesterone $(\mathrm{P})$ and oestradiol $\left(\mathrm{E}_{2}\right) 4$ and $8 \mathrm{~h}$ after unilateral ovariectomy on diocstrus 2 (means \pm SEM).

the night before implantation). Four and $8 \mathrm{~h}$ after unilateral ovariectomy (ULO) peripheral levels of FSH were significantly increased when compared with intact control animals. Concomitantly, decreased progesterone levels were cbserved, while LH (data not shown) and oestradiol levels were not significantly different in ULO and sham operated groups (Fig. 5). After implantation of the silastic tubing, filled with progesterone, peripheral progesterone levels were

Table 1 .

Effects of implanted progesterone or injected steroid-free follicular fluid on peripheral concentrations of progesterone and FSH in intact animals and $4 \mathrm{~h}$ after unilateral ovariectomy (ULO) on dioestrus- 2 in female rats (means \pm SEM, $n=5$ ).

\begin{tabular}{|c|c|c|c|}
\hline \multirow{2}{*}{ ULO } & \multirow{2}{*}{ Treatment } & \multicolumn{2}{|c|}{$\begin{array}{c}\text { Concentrations }(\mathrm{ng} / \mathrm{ml}) \text { in } \\
\text { peripheral plasma }\end{array}$} \\
\hline & & Progestercne & FSH \\
\hline- & Empty implant & $58 \pm 19$ & $100 \pm 16$ \\
\hline+ & Empty implant & $65 \pm 8$ & $194 \pm 19:$ \\
\hline$\therefore$ & Progesterone implant & $111 \pm 12^{* *}$ & $174 \pm 11^{*}$ \\
\hline - & Bovine plasma & - & $87 \pm 8$ \\
\hline+ & Bovine plasma & - & $174 \pm 13$ \\
\hline+ & Follicular fluid & - & $65 \pm 4$ \\
\hline
\end{tabular}

- Significantly different from sham operated controls.

$*$ Significantly different from control ULO rats. 
doubled, while FSH concentrations were not affected. Injection of FF effectively suppressed the increase of FSH levels after ULO (Table 1).

Influence of prolonged daily administration of $F F$ on gonadotrophins and gonadal function. - Adult female rats and 21 day old male rats were injected daily with FF or BP. The female animals were bled at various intervals and vaginal smears were taken daily. The injections $(0.25 \mathrm{ml} / 100 \mathrm{~g} \mathrm{~b}$. w. until day $17,1.0 \mathrm{ml} / 100 \mathrm{~g} \mathrm{~b} . \mathrm{w}$. during the rest of the experiment) started on dioestrus 2 and were continued until the fifth oestrous smear was observed. Serum FSH levels were suppressed $8 \mathrm{~h}$ after the first injection, and then increased. On day 17 and 26, FSH concentrations in the samples from the FF treated animals were significantly higher than in BP treated controls (Fig. 6). LH levels were significantly increased on days 10,17 and 26. Vaginal cycles were not disturbed during the experimental period. At the second and fifth oestrus groups of animals were killed and tubae were checked for the presence of ova. Numbers of tubal ova in the FF and BP treated groups were not significantly different (Table 2).

Daily injections of $\mathrm{FF}$ or $\mathrm{BP}(0.50 \mathrm{ml} / 100 \mathrm{~g} \mathrm{b.w}$.) into groups of immature male rats, starting on day 21 of life and continued for periods of 1, 2, 4,6 or 12 days resulted in the data shown in Table 3 . Numbers of pachytene spermatocytes in $5 \mu \mathrm{m}$ sections of the testes of the 27 and 33 days old rats, were estimated as described by de Jong \& Sharpe (1977).

Fig. 7 shows the relationship between the number of pachytene spermatocytes per tubular cross-section and the stage of the cycle of the spermatogenic epithelium (Leblond \& Clermont 1952) of that cross-section. The slope of the

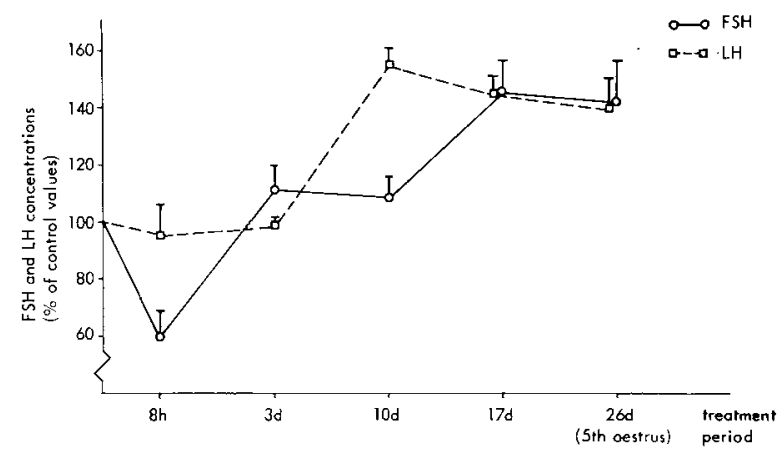

Fig. 6 .

Relative serum concentrations of LH and FSH in female rats, injected daily with bovine follicular fluid $(0.25 \mathrm{ml} / 100 \mathrm{~g} \mathrm{~b}$. w. during 17 days and $1.0 \mathrm{ml} / 100 \mathrm{~g} \mathrm{~b}$. w. afterwards) (means \pm sEM). 
Table 2.

Effects of daily treatment with bovine plasma or follicular fluid on mean cycle length in days and number of tubal ova at fifth oestrus after start of treatment.

\begin{tabular}{c|ccccc|c}
\hline & \multicolumn{4}{|c|}{ Treatment } & \multicolumn{4}{c|}{$\begin{array}{c}\text { Mean cycle length during cycle } \\
\end{array}$} & 1 & 2 & 3 & 4 & $\begin{array}{c}\text { Mean } \\
\text { number } \\
\text { of ova }\end{array}$ \\
\hline Bovine plasma & 6.6 & 6.4 & 5.9 & 5.7 & 9.0 \\
Follicular fluid & 6.4 & 5.5 & 5.3 & 5.7 & 11.4 \\
\hline
\end{tabular}

regression line for the 6 days $\mathrm{FF}$ treated rats was significantly different from that for the other groups; the slopes of the regression lines for the other groups were not significantly different from each other. The intercepts for the FF treated groups were significantly different from those for the BP treated animals of the same age. However, the intercept for the 12 days FF group is not significantly different from that for the 6 days BP treated animals.

Table 3.

Testis weights and serum gonadotrophin concentrations in male rats, after daily injections with $0.50 \mathrm{ml}$ follicular fluid/100 $\mathrm{g} \mathrm{b}$ b. starting on day 21 of life. All values are given as percentage of values in bovine plasma treated controls (means $\pm \mathrm{sD}, \mathrm{n}=6$ ).

\begin{tabular}{c|c|c|c}
\hline $\begin{array}{c}\text { Length of } \\
\text { treatment } \\
\text { (days) }\end{array}$ & Testis weight & FSH & LH \\
\hline 1 & $100 \pm 4$ & $26 \pm 6^{*}$ & $150 \pm 30$ \\
2 & $90 \pm 10$ & $29 \pm 8^{*}$ & $260 \pm 127^{*}$ \\
4 & $81 \pm 8^{*}$ & $35 \pm 10^{*}$ & $200 \pm 50^{*}$ \\
6 & $63 \pm 9^{*}$ & $84 \pm 14$ & $117 \pm 5^{*}$ \\
12 & $64 \pm 13^{*}$ & $72 \pm 32$ & $178 \pm 43^{*}$ \\
\hline
\end{tabular}

* Significantly different from control. 


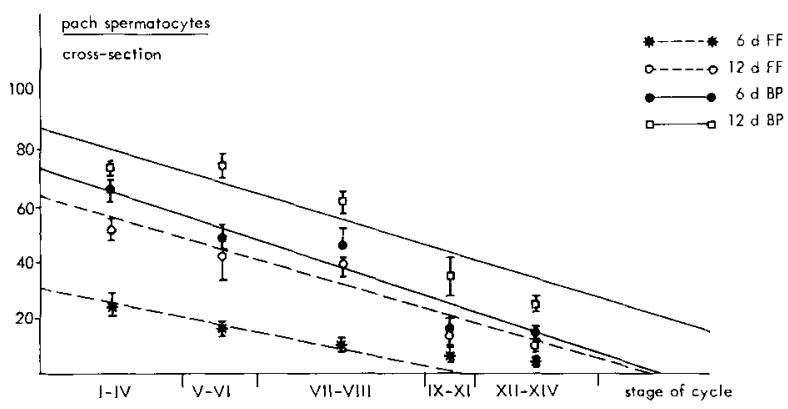

Fig. 7 .

Relationship between number of pachytene spermatocytes per tubular cross-section and stage of the spermatogenic cycle in rats, treated with bovine plasma (BP) or follicular fluid (FF) $(0.50 \mathrm{ml} / 100 \mathrm{~g} \mathrm{~b} . w . /$ day) for 6 or 12 days, starting on day 21 of age (means \pm sem, $n=3-18$ ).

\section{Discussion}

The dose response curves for the FF or SCCM induced suppression of the release of FSH by cultured pituitary cells were parallel for all 3 conditions tested: the spontaneous release of $\mathrm{FSH}$ during a 3 day culture period, the LH-RH stimulated FSH release during $6 \mathrm{~h}$ and the cellular content of FSH after these treatments. This could indicate that inhibin-like activities from ovary and testis regulate the release and the production of FSH by the same mechanism. This is one of the requirements to be fulfilled if ovarian and testicular inhibin have a similar nature.

It is not clear if the stimulation of LH release during the 3 days culture period after addition of SCCM (Fig. 1) or large amounts of FF and the suppression of LH release by FF and SCCM during the $6 \mathrm{~h}$ culture period with LH-RH (Fig. 2) are caused by inhibin, or by other factors which might be present in FF or SCCM. The discrepancy between the amounts of FF and SCCM, that had to be used to obtain maximal suppression of FSH ( 1 and $1000 \mu \mathrm{l}$, respectively) and the amounts of FF and SCCM necessary to double the release of LH during the 3 day culture period (200 and $1000, \mu$, respectively), suggests that different factors could play a role in these phenomena.

The effects of injection of $\mathrm{FF}$ into male and female rats were largely comparable: serum FSH was suppressed in a dose related way (Fig. 3), while LH concentrations were not consistently affected in short term experiments. The sensitivity of the animal to the inhibin-like activity (defined in terms of the degree of FSH suppression obtained and the time required for the first decrease of the peripheral FSH concentration) seems to be highest in the 35 days old and adult female rats. This sensitivity might be related to the previous exposure 
of the animal's pituitary to endogenous inhibin-like activity, since the circulating concentration of FSH in the 5 days old female rat did not respond to injection of FF, unless the animals were pretreated with $\mathrm{FF}$. This suggestion is supported by the observation of Welschen et al. (1977) that long-term ovariectomy abolished the $4 \mathrm{~h}$ response to $\mathrm{FF}$ in adult female rats.

The results obtained in the ULO rats indicate that inhibin might be a regulatory factor in the cycle of the female rat. The increase in FSH occurs in a situation where peripheral oestradiol concentrations do not change (Fig. 5), as has also been shown by Butcher (1977). It cannot be suppressed with twice the physiological concentration of progesterone, but small amounts of steroidfree FF can maintain the concentration of FSH at the control level, without affecting LH concentrations. Finally, the peripheral FSH concentration in otherwise untreated ULO rats drops to control levels $28 \mathrm{~h}$ after the operation, at the time when the remaining ovary contains two times more large follicles than one ovary in an intact animal (Welschen et al. 1978). These observations could reflect that inhibin plays a role in the short term regulation of the number of developing follicles in the ovary.

In contrast to the short term effects of treatment with FF, daily treatment of adult female or immature male animals failed to suppress peripheral FSH levels for longer periods (Fig. 6, Table 3). As a consequence, the effects on the gonads seem to be temporary also: the cycle in the female rat is not disturbed (Table 2) and in the male animals the testes seem to resume their development after a delay of about 6 days, as judged from testicular weight and numbers of pachytene spermatocytes per tubular cross-section (Fig, 7). The mechanism for the compensation or overcompensation of the circulating concentrations of FSH and LH during continuous treatment with FF is not clear, but unless this effect is due to factors in FF which are different from inhibin, the possibility of long term regulation of fertility by administration of inhibin seems remote.

\section{Acknowledgments}

This study was supported in part by the Dutch Foundation for Medical Research (FUNGO). We are grateful to the National Institute of Arthritis and Metabolic Diseases, USA, for the supply of gonadotrophins used in the radioimmunoassays.

\section{References}

Borth R. (1976) Statistics of parallel line assay. In: Breuer H., D. Hamel \& H. L. Krüskemper, Eds. Methods of Hormone Analysis, p. 500. Thieme Verlag, Stuttgart.

Butcher R. L. (1977) Changes in gonadotropins and steroids associated with unilateral cvariectomy of the rat. Endocrinology 101, 830. 
Caravaglios R. \& R. Cilotti (1957) A study of the proteins in the follicular fluid of the cow. J. Endocr. 15, 273.

Denef C., E. Hautekeete \& E. Rubin (1976) A specific population of gonadotrophs purified from immature female rat pituitary. Science 194, 848.

Franchimont P., S. Chari, M. T. Hagelstein \& S. Duraiswami (1975) Existence of a follicle-stimulating hormone inhibiting factor 'inhibin' in bull seminal plasma. Nature (Lond.) 257, 402.

Howland B. E. \& K. R. Skinner (1973) Effect of hemiovariectomy on serum FSH and LH levels during the oestrus cycle in the rat. J. Reprod. Fertil. 32, 501.

de Jong F. H., A. H. Hey \& H. J. van der Molen (1973) Effects of gonadotrophins on the secretion of oestradiol-17 $\beta$ and testosterone by the rat testis. J. Endocr. 57, 277.

de Jong F. H., D. T. Baird \& H. J. van der Molen (1974) Ovarian secretion rates of cestrogens, androgens and progesterone in normal women and in women with persistent ovarian follicles. Acta endocr. (Kbh.) 77, 575.

de Jong F. H. \& R. M. Sharpe (1976) Evidence for inhibin-like activity in bovine follicular fluid. Nature (Lond.) 263, 71.

de Jong F. H. \& R. M. Sharpe (1977) The onset and establishment of spermatogenesis in rats in relation to gonadotrophin and testosterone levels. J. Endocr. 75, 197.

Keogh E. J., V. W. K. Lee, G. C. Rennie, H. G. Burger, B. Hudson \& D. M. de Kretser (1976) Selective suppression of FSH by testicular extracts. Endocrinology 98, 997.

Leblond C. P. \& Y. Clermont (1952) Spermiogenesis of rat, mouse, hamster and guinea pig as revealed by the 'periodic acid-fuchsin-sulphurous acid' technique. Amer. J. Anat. 90, 167.

Marder M. L., C. P. Channing \& N. B. Schwartz (1977) Suppression of serum follicle stimulating hormone in intact and acutely ovariectomized rats by porcine follicular fluid. Endocrinology 101, 1639.

McCullagh D. R. (1932) Dual endocrine activity of the testes. Science 76, 19.

Means A. R., J. L. Fakunding, C. Huckins, D. J. Tindall \& R. Vitale (1976) Folliclestimulating hormone, the Sertoli cell and spermatogenesis. Recent Progr. Hormone Res. 32, 477.

Nandini S. G., H. Lipner \& N. R. Moudgal (1976) A model system for studying inhibin. Endocrinology 98, 1460.

Ramirez V. D. \& C. H. Sawyer (1974) A sex difference in the rat pituitary response to unilateral gonadectomy as revealed in plasma radioimmunoassays. Endocrinology 94,475 .

Rommerts F. F. G., B. Ch. Krüger-Sewnarain, A. van Woerkom-Blik, J. A. Grootegoed \& H. J. van der Molen (1978) Secretion of proteins by Sertoli cell enriched cultures: Effects of follicle stimulating hormone, dibutyryl-cAMP and testosterone and correlation with secretion of oestradiol and androgen binding protein. Mol. Cell Endocr. $10,39$.

Setchell B. P. \& F. Jacks (1974) Inhibin-like activity in rete testis fluid. J. Endocr. 62,675 .

Steinberger A. \& E. Steinberger (1976) Secretion of an FSH inhibiting factor by cultured Sertoli cells. Endocrinology 99, 918.

Welschen R. \& J. Dullaart (1974) Serum concentrations of follicle-stimulating hormone and luteinizing hormone after unilateral ovariectomy in the adult rat. J. Endocr. $63,421$.

Welschen R., P. Osman, J. Dullaart, W. J. de Greef, J. Th. J. Uilenbroek \& F. H. de Jong (1975) Levels of follicle-stimulating hormone, luteinizing hormone, oestra- 
diol-17 $\beta$ and progesterone, and follicular growth in the pseudopregnant rat. J. Endocr. $64,37$.

Welschen R., W. P. Hermans, J. Dullaart \& F. H. de Jong (1977) Effects of an inhibinlike factor present in bovine and porcine follicular fluid on gonadotrophin levels in ovariectomized rats. J. Reprod. Fertil. 50, 129.

Welschen R., J. Dullaart \& F. H. de Jong (1978) Interrelationships between circulating levels of oestradiol-17 $\beta$, progesterone, FSH and LH immediately after unilateral ovariectomy in the cyclic rat. Biol. Reprod. (in press).

\section{I S C USS I O N}

A. Steinberger: These are extremely interesting data, Dr. de Jong. I would like to comment, however, on the effect of follicular fluid on spermatogenesis in vivo. I was not surprised that you found no significant effect on the number of spermatocytes following 6 or 12 days of injections of the follicular fluid into immature rats. Since, FSH appears to be required for the final steps of spermiogenesis, it would be very important to assess the effect of follicular fluid on spermatid maturation during the initial wave of spermatogenesis.

de Jong: In fact, we found a significant effect on numbers of pachytene spermatocytes, both after 6 and 12 days of treatment with follicular fluid (FF), when the data were compared with those of the 6 and 12 days bovine plasma (BP) treated control animals. However, the numbers of pachytene spermatocytes in the 12 day FF treated rats did not differ from those of the 6 day BP-treated animals, as we might expect if the suppression of FSH lasts for 6 days and no direct effects of FF on spermatogenesis are present.

Raj: It was very interesting to note that "inhibin" treatment was not effective after 6 day period. Dr. Dym and I have shown anti FSH treatment to immature rat for 15 days results in reduction of germ cell numbers. What, in your opinion, are the reasons for this "inability" of inhibin to suppress FSH after 6th day of treatment?

de Jong: The only guess I could make at the moment is a mechanism through decreased steroid levels as a consequence of the decreased FSH concentrations. This might cause an increase in the release of LH-RH from the hypothalamus, with increased LH concentrations and "back-to-normal" FSH levels as a result.

Raj: The female rat is a multiple ovulator. At each ovulation, a considerable amount of follicular fluid escapes into the peritoneal cavity. Thus the rat gives itself "self injection" of the fluid at each ovulation. This may effect the short term regulation of FSH you described and also may have long term implications for selection of follicles for subsequent cycles. 